\title{
Pharma payment probe widens its net
}

US senator Charles Grassley (Republican, Iowa) is no Sigmund Freud, but since early this year he has succeeded in putting the psychiatric establishment on the couch. Grassley, the senior Republican on the Senate finance committee, has detailed how eight prominent academic researchers (see 'Show me the money') failed to obey rules and report to their universities payments from drug companies, some running into seven figures. Every one of those researchers is a psychiatrist.

Grassley has denied singling out psychiatry, and is now demanding that Columbia University in New York produce financial-disclosure documentation for 22 cardiologists. But his revelations - along with his demand this summer that the American Psychiatric Association (APA), based in Arlington, Virginia, document its drug-company income - have created the impression, fair or otherwise, that academic psychiatry is permeated with oftenundisclosed drug-company payments, biasing its findings, possibly harming patients and certainly eroding public trust.

As psychiatry has been reshaped by a wave of new medications during the past two decades, insurers have made it more lucrative for psychiatrists to prescribe drugs rather than conduct psychotherapy. Because those medications are often big money-makers for industry as well, "what you end up with is a very powerful and potentially corrupting relationship between pharmaceutical companies and psychiatrists," says Paul Root Wolpe, director of the Center for Ethics at Emory in Atlanta, Georgia.

Arguably, Grassley's biggest catch so far has been Charles Nemeroff, formerly chairman of psychiatry at Emory, who last week stepped aside as principal investigator or co-investigator on grants funded by the National Institutes of Health. According to documents released this month by Grassley, Nemeroff broke university and federal rules by failing to disclose at least $\$ 1.2$ million in drug-company income between 2000 and 2006 (see Nature 455, 835; 2008).

Nada Stotland, the president of the APA, suggests that Grassley's focus on psychiatry may reflect historical prejudice against the speciality. "There are conditions of similar magnitude, if not greater, in other specialities of medicine," she says. "It's a serious concern to me and the organization, the profession, why we are only hearing about psychiatrists."

Stotland, a professor of psychiatry at Rush Medical College in Chicago, who earns no money from companies, says that the APA receives $29 \%$ of its $\$ 56$-million annual budget

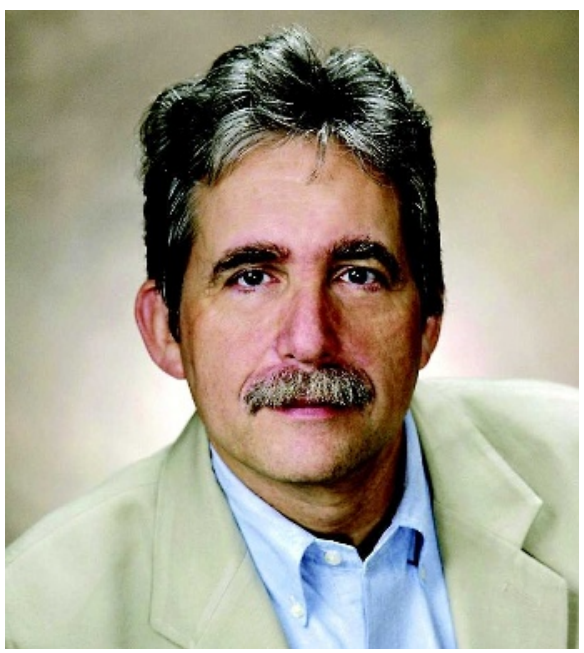

Charles Nemeroff failed to disclose more than US\$1 million in income from drug companies.

from drug companies, about half of which derives from advertising revenue for its three journals. The APA, she contends, is an exemplar of vigilant conflict policing - requiring, for example, that no one with a combined drugcompany income of more than $\$ 10,000$ may sit on the committee that updates its standardsetting diagnostic manual.

A 2007 study by the New York Times looked at trends in payments to physicians in Minnesota, one of the few states requiring drug

\section{Show me the money}

US Senator Charles Grassley's investigation has so far alleged that eight psychiatrists failed to declare payments from drug companies during the period 2000-07:

Joseph Biederman, Harvard University, Boston

Melissa DelBello, University of Cincinnati, Ohio

Charles Nemeroff, Emory University, Atlanta, Georgia

Augustus John Rush, University of Texas Southwestern Medical Center at Dallas

Alan Schatzberg, Stanford University,

California

Thomas Spencer, Harvard University

Karen Wagner, University of Texas Medical Branch, Galveston

Timothy Wilens, Harvard University companies to publicly post such payments. It found that, between 2000 and 2005, psychiatrists as a group collected more money from drug companies than doctors in any other speciality. It also found a striking relationship between drug-company payments and prescriptions made to children of a controversial but lucrative class of drugs called atypical antipsychotics. On average, psychiatrists who received at least $\$ 5,000$ from makers of these drugs wrote three times as many prescriptions for children as psychiatrists who received less or no money.

Experts say that a confluence of factors have made psychiatry vulnerable to drug-company influence. First, name-brand psychiatric drugs for a given disease may differ very little from each other, making the blessings of prominent specialists important in giving a particular drug the edge. Second, psychiatric drugs can be extremely lucrative. For instance, in 2007, Zyprexa (from Eli Lilly), Risperdal (from Johnson \& Johnson) and Seroquel (from AstraZeneca), all leading atypical antipsychotics, earned $\$ 4.8$ billion, $\$ 4.5$ billion and $\$ 4.0$ billion, respectively.

But because specific psychiatric drugs don't work for every patient, and their performance in given cases is hard to predict, there's an element of judgment and even guesswork involved in prescribing them, says Charles Jennings, who directs the neurotechnology programme at the McGovern Institute for Brain Research at the Massachusetts Institute of Technology in Cambridge. "That may be one reason why drug companies invest so much in promoting these drugs," he says. "When the evidence is marginal, every little bit counts." (Jennings was editor of Nature Neuroscience in 2002 when the journal published a review by Nemeroff that brought him under fire for failing to disclose conflicts of interest (B. J. Carroll \& R. T. Rubin Nature Neurosci. 6, 999-1000; 2003). Jennings was also involved in developing the Nature journals' disclosure policy for authors.)

Then there is the simple fact that psychiatrists earn considerably less than medics in many other specialist fields. In 2007, the median income for psychiatrists was $\$ 199,000$, according to the Medical Group Management Association. Anaestheiologists, by contrast, made $\$ 400,000$, and dermatologists $\$ 366,000$. "I don't think that's irrelevant," says Wolpe. "I think low-paid specialities, especially in today's economic and medical climate, look for ways to increase their income."

Meredith Wadman 